\title{
Fatty acids of reef-building corals
}

\author{
N. A. Latyshev ${ }^{1}$, N. V. Naumenko ${ }^{2}$, V. I. Svetashev ${ }^{1}$, Y. Ya. Latypov ${ }^{1}$ \\ ${ }^{1}$ Institute of Marine Biology, Far East Branch of Academy of Sciences of the USSR, Vladivostok 690032, USSR \\ ${ }^{2}$ Department of Bioorganic Chemistry, Far East State University, Vladivostok 690000, USSR
}

\begin{abstract}
Fourteen reef-building coral species of Anthozoa and Hydrozoa classes, collected in various regions of the Indo-Pacific, were analyzed for fatty acid composition by gas-liquid chromatography. Total lipids of the corals had the same set of fatty acids. The main fatty acids were 16:0, 18:0 $18: 1(n-9), 20: 4(n-6), 20: 5(n-3)$ and $22: 6(n-3)$, but some coral families had significant levels of characteristic fatty acids: Pocilloporidae - 20:3(n-6); Acroporidae - 18:3(n-6), 18:4(n-3) and 22:4(n-6); Poritidae - 18:3(n-6); Milleporidae - 22:4(n-6), 22:5(n-6) and 22:6(n-3). Related species of Pocilloporidae from Vietnam and Seychelles differed greatly in their content of saturated acids - 50 to $60 \%$ and $30 \%$, respectively. As shown for Stylophora pistillata, the depth of the habitat affects the degree of fatty acid unsaturation and $(n-3) /(n-6)$ ratio of neutral lipids, but does not affect phospholipid fatty acids. A possible role of $\Delta 5$ - and $\Delta 4$ - desaturases in determining fatty acid pool formation in reefbuilding corals is discussed with reference to their nutritional characteristics.
\end{abstract}

\section{INTRODUCTION}

Lipids are the main source of stored energy in the Coelenterata. Zooxanthellae associated with corals are important primary producers in the nutrition chain in tropical shallow-water communities (Benson \& Muscatine 1974, Patton et al. 1983, Stimson 1987). The composition of fatty acids depends greatly on the currently prevailing food source (Meyers 1979). The capacity of coelenterates for polytrophic feeding, including external food sources such as dissolved organic matter and plankton, is well documented (Schlichter 1982). However, an essential contribution to coral nutrition is made by zooxanthellae (Patton et al. 1977. Muscatine 1980). It has been shown by many authors that photosynthetically fixed carbon is rapidly transformed into lipids, which are then carried into 'host' tissues in the form of 'fat droplets', consisting of triglycerides, wax esters and free fatty acids (Patton et al. 1983). These 'fat droplet' lipids are the main source of saturated fatty acids, while the presence of polyunsaturated fatty acids (PUFA) is most probably indicative of external food sources such as zoo- and phytoplankton (Kellogg \& Patton 1983).

Studies of fatty acids of reef-building corals have not so far been systematic, although there are papers dealing with the fatty acid composition of some lipid classes (Benson \& Muscatine 1974, Meyers 1977, 1979, Patton et al. 1983). Data on PUFA contents of total lipids of reef-building corals are limited and inconsistent: they range from complete absence of PUFA to as much as $82.8 \%$ of $22: 6(n-3)$ acid in the total fatty acid content (Meyers 1977, Meyers et al. 1974). Earlier, we attempted to use fatty acids as taxonomic markers in Scleractinia corals (Latypov et al. 1988). However, no convincing proof of any connection between fatty acid composition and coral taxonomy was obtained.

The objective of this paper is to show a correlation between ecological factors and composition and distribution of fatty acids in common hermatypic corals and hydrozoans.

\section{MATERIALS AND METHODS}

The study was carried out in December to March 1987-1988 and 1988-1989 during expeditions of the RV 'Akademik Nesmeyanov'. Eleven species of Scleractinia and 3 species of Milleporina corals were collected by SCUBA divers in the South China Sea (Vietnam; Thotyu $\left(8^{\circ} 45^{\prime} \mathrm{N}, 106^{\circ} 38^{\prime} \mathrm{E}\right)$ and Tyam $\left(15^{\circ} 57^{\prime} \mathrm{N}, 108^{\circ} 31^{\prime} \mathrm{E}\right)$ Islands) and Indian Ocean (Seychelles; Aldabra and Coetivy Islands). Whole live colonies of various forms were sampled on reef-flats, slopes and platforms at 1.5 to $15 \mathrm{~m}$ depths. Samples of Stylopora pistillata were collected near Aldabra from depths 3, 9, 25 and $35 \mathrm{~m}$. Corals were identified by the taxonomic scheme of Wells (1956). The corals were 
Table 1. Fatty acid composition of total lipids of scleractinian corals: family Acroporidae. ( $\%$ of total fatty acids, values more than $0.2 \%$ are given). PUFA: polyunsaturated fatty acids

\begin{tabular}{|c|c|c|c|c|c|}
\hline \multirow[t]{2}{*}{ Fatty acids } & \multicolumn{5}{|c|}{ Anthozoa: Acroporidae } \\
\hline & $\begin{array}{c}\text { Acropora } \\
\text { nasuta } \\
\text { Vietnam }^{a}\end{array}$ & $\begin{array}{c}\text { Acropora } \\
\text { nasuta } \\
\text { Vietnam }^{\mathrm{b}}\end{array}$ & $\begin{array}{l}\text { Acropora } \\
\text { millepora } \\
\text { Vietnam }^{\circ}\end{array}$ & $\begin{array}{l}\text { Acropora } \\
\text { millepora } \\
\text { Vietnam }^{b}\end{array}$ & $\begin{array}{c}\text { Acropora } \\
\text { florida } \\
\text { Vietnam }^{b}\end{array}$ \\
\hline $14: 0$ & 5.4 & 2.5 & 1.2 & 3.6 & 2.7 \\
\hline $16: 0$ & 42.5 & 38.6 & 24.5 & 41.3 & 33.1 \\
\hline $16: 1(n-7)$ & 0.8 & 1.0 & 1.0 & 2.6 & 1.2 \\
\hline $16: 2$ & - & 1.8 & - & 0.7 & - \\
\hline $18: 0$ & 6.9 & 7.3 & 9.3 & 8.7 & 9.0 \\
\hline $18: 1(n-9)$ & 3.7 & 8.0 & 2.2 & 6.5 & 3.2 \\
\hline $18: 2(n-6)$ & 0.7 & 2.1 & 1.1 & 1.7 & 1.3 \\
\hline $18: 3(n-6)$ & 9.7 & 5.8 & 9.5 & 5.0 & 8.2 \\
\hline $18: 4(n-3)$ & 4.9 & 2.6 & 6.6 & 1.1 & 5.1 \\
\hline $20: 0$ & - & 0.5 & - & 1.3 & - \\
\hline $20: 1$ & 1.3 & 0.7 & 1.1 & 1.6 & 1.0 \\
\hline $20: 2(n-6)$ & 0.2 & 2.0 & 0.2 & 0.7 & 0.5 \\
\hline $20: 3(n-6)$ & 2.3 & 1.9 & 2.4 & 2.0 & 0.3 \\
\hline $20: 4(n-6)$ & 3.2 & 7.1 & 7.2 & 8.0 & 11.0 \\
\hline $20: 4(n-3)$ & 0.3 & 0.2 & - & 0.5 & - \\
\hline $20: 5(n-3)$ & 4.5 & 0.8 & 10.4 & 1.6 & 6.9 \\
\hline $22: 3(n-6)$ & - & - & - & 0.6 & 0.3 \\
\hline $22: 4(n-6)$ & 2.4 & 4.3 & 6.0 & 1.0 & 6.3 \\
\hline $22: 5(n-6)$ & 0.3 & - & 0.6 & - & 1.3 \\
\hline $22: 5(n-3)$ & 1.3 & 0.9 & 3.0 & 0.5 & 1.2 \\
\hline $22: 6(n-3)$ & 8.8 & 10.8 & 12.6 & 10.4 & 6.7 \\
\hline Saturated & 54.8 & 48.9 & 35.0 & 54.8 & 44.8 \\
\hline PUFA & 38.7 & 40.4 & 59.6 & 33.8 & 49.4 \\
\hline$(n-3) /(n-6)$ & 1.1 & 0.6 & 1.2 & 0.7 & 0.7 \\
\hline
\end{tabular}

placed into tanks under water at the site of collection and transported to the ship within $0.5 \mathrm{~h}$. Combined samples from 3 to 5 colonies were crushed into 1 to $3 \mathrm{~mm}$ pieces and total lipids were extracted with intensive stirring in a chloroform-methanol $(2: 1 \mathrm{v} / \mathrm{v})$ mixture $(3 \times 30 \mathrm{ml}$ for $10 \mathrm{~g}$ of coral weight). The extracts were then mixed, and separated into layers by adding $20 \mathrm{ml}$ of water and $20 \mathrm{ml}$ of chloroform. The lower layer was evaporated and redissolved in chloroform. Total lipids were divided into polar and neutral fractions by silica gel column chromatography. Neutral lipids (triacylglycerols, sterols, free fatty acids and waxes) were eluted with chloroform; polar lipids (phospholipids and glycolipids) were eluted with chloroform-methanol $(1: 1 \mathrm{v} /$ v). Methyl esters of the fatty acids (FAME) were obtained by the method of Carreau \& Dubacq (1978), and methyl esters were purified by thin-layer chromatography (TLC) using benzene as a solvent. The esters were eluted with chloroform and redissolved in hexane. A gas chromatograph GC-9A with a data station Chromatopac C-R3A (Shimadzu, Japan) was used for FAME analysis. A quartz capillary column, $25 \mathrm{~m} \times$ $0.25 \mathrm{~mm}$, coated with FFAP (Supelco Inc, Bellefonte, PA, USA) was used at operating temperature $180^{\circ} \mathrm{C}$, with carrier gas helium. Fatty acids were identified according to standards and using equivalent chain length (ECL) values (Flanzy et al. 1976). Separation by degree of unsaturation was carried out on silica gel TLC plates impregnated with $\mathrm{AgNO}_{3}$.

\section{RESULTS}

Tables 1 to 5 show the data on distribution of fatty acids in total lipids of 11 Scleractinia species belonging to 4 families, and of 3 Milleporidae species.

Class Anthozoa; Family Acroporidae (Table 1). These corals were collected only off Tyam and Thotyu Islands. Saturated acids (16:0 and 18:0) were predominant in all species. Among PUFA, $18: 3(n-3)^{\circ}$, $20: 4(n-6), 20: 5(n-3)$, and 22:6(n-3) prevailed. Analysis of Acropora millepora revealed that fatty acid composition of corals from various habitats showed considerable intraspecific variation. For instance, PUFA of cor-

\footnotetext{
- Fatty acids are designated as total number of $C$ atoms: number of double bonds $(n-x)$ ' where $x$ is the position of the ultimate double bond from the terminal methyl group
} 
Table 2. Fatty acid composition of total lipids of scleractinian corals: family Pocilloporidae. $(\%$ of total fatty acids, value more than $0.2 \%$ are given). PUFA: polyunsaturated fatty acids

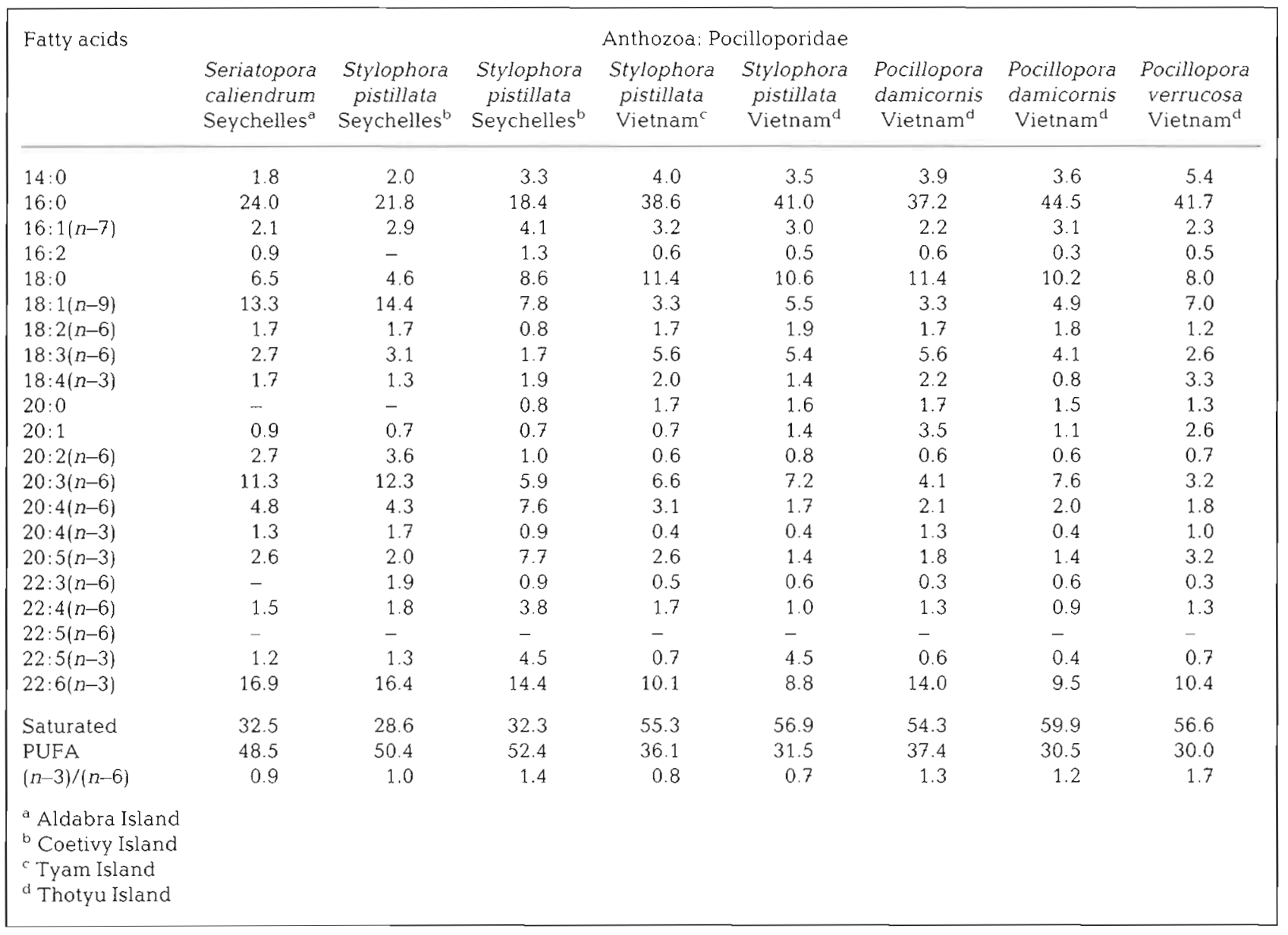

als from Tyam (coastal hydrological regime) contributed about $60 \%$ of total acids, mostly due to a raised fraction of $(n-3)$ acids, while lipid unsaturation of $A$. millepora from Thotyu (open sea hydrological regime) was only $34 \%$. Similarly raised $(n-3)$ acids were found in A. nasuta.

Family Pocilloporidae (Table 2). Since the Pocilloporidae species were widely represented on all the reefs, this family was examined in detail. All specimens from the South China Sea were distinguished by a high degree of unsaturation of fatty acids ( 49 to $57 \%$ ), while those from the Seychelles corals did not exceed $32.5 \%$. The ratio $(n-3) /(n-6)$ acids was not distinctly related to the geographical region of coral habitat. In general, the Pocilloporidae are distinguished by a content of icosatrienoic [20:3(n-6)] acid unusually high for invertebrates. It was the main acid of the $(n-6)$ series, quantitatively exceeding arachidonic [20:4(n-6)] acid in all species examined except one. Such an unusual content of $20: 3(n-6)$ acid in the coral total lipids impelled us to examine the distribution of these acids in Stylophora pistillata collected from various depths on Aldabra.
Colony form and length and breadth of branches in coral changed considerably with depth increase from 3 to $35 \mathrm{~m}$. At a depth 3 to $5 \mathrm{~m}$ on the reef-flat and on the upper part of the reef-slope, colonies had a submassive hemispherical form with short, broad branches almost touching each other. Colonies with well-developed dichotomic branches 5 to $10 \mathrm{~cm}$ long and 6 to $16 \mathrm{~cm}$ broad prevailed on the reef-slope. At the base of the slope and near-slope platform ( 30 to $35 \mathrm{~m}$ ), only ramose colonies with thin (2 to $5 \mathrm{~mm})$ and long $(10$ to $16 \mathrm{~cm}$ ) dichotomic branches were found.

Polar lipids of Stylophora pistillata of all colony forms from 3 to $35 \mathrm{~m}$ depth did not differ significantly in degree of unsaturation and ratio $(n-3) /(n-6)$ of acids (Table 3). However there were some shifts in the contents of particular fatty acids. Most visible was an increased amount of $18: 3(n-6)$ and a decrease in $20: 5(n-3)$. In neutral lipids, a pronounced increase with depth was observed in the amounts of $18: 1(n-9)$ and $22: 6(n-3)$ acids, and a decrease in 20:5(n-3). Icosatrienoic acid $[20: 3(n-6)]$ was found mainly in neutral lipids 
Table 3. Stylopora pistillata. Fatty acid composition of polar and neutral lipids at (Aldabra Island) (Seychelles) as a function of depth ( $\%$ of total fatty acids). Values more than $0.2 \%$ are given

\begin{tabular}{|c|c|c|c|c|}
\hline \multirow{2}{*}{$\begin{array}{l}\text { Fatty } \\
\text { acids }\end{array}$} & \multicolumn{4}{|c|}{ Depth in meters } \\
\hline & 3 & 9 & 25 & 35 \\
\hline \multicolumn{5}{|l|}{ Polar lipids } \\
\hline $14: 0$ & 0.8 & 1.2 & 0.7 & 0.8 \\
\hline $16: 0$ & 4.2 & 4.2 & 5.8 & 4.3 \\
\hline $16: 1(n-7)$ & 1.0 & 1.5 & 1.7 & 0.3 \\
\hline $16: 2$ & - & 0.4 & 0.5 & 0.4 \\
\hline $18: 0$ & 5.6 & 11.1 & 9.8 & 8.6 \\
\hline $18: 1(n-9)$ & 0.8 & 1.5 & 2.3 & 2.4 \\
\hline $18: 2(n-6)$ & 0.5 & 0.7 & 1.1 & 1.0 \\
\hline $18: 3(n-6)$ & 0.9 & 1.1 & 7.7 & 8.1 \\
\hline $18: 4(n-3)$ & 4.9 & 8.6 & 14.5 & 10.9 \\
\hline $20: 0$ & 0.3 & 0.4 & 1.3 & 1.0 \\
\hline $20: 1$ & - & 0.4 & 0.5 & 0.4 \\
\hline $20: 2(n-6)$ & 3.7 & 1.9 & 1.3 & 0.9 \\
\hline $20: 3(n-6)$ & 1.6 & 0.5 & 1.8 & - \\
\hline $20: 4(n-6)$ & 25.3 & 19.0 & 17.0 & 25.0 \\
\hline $20: 4(n-3)$ & 0.3 & - & - & - \\
\hline $20: 5(n-3)$ & 23.8 & 19.9 & 12.0 & 11.8 \\
\hline $22: 3(n-6)$ & - & - & - & - \\
\hline $22: 4(n-6)$ & 9.4 & 10.5 & 8.4 & 8.4 \\
\hline $22: 5(n-6)$ & - & - & - & - \\
\hline $22: 5(n-3)$ & 2.6 & 3.6 & 1.9 & 1.6 \\
\hline $22: 6(n-3)$ & 9.0 & 6.6 & 7.5 & 8.4 \\
\hline Saturated & 11.0 & 17.0 & 17.9 & 15.0 \\
\hline PUFA & 83.7 & 74.7 & 76.1 & 79.9 \\
\hline$(n-3) /(n-6)$ & 1.0 & 1.1 & 1.0 & 0.8 \\
\hline \multicolumn{5}{|l|}{ Neutral lipids } \\
\hline $14: 0$ & 3.6 & 2.8 & 1.0 & 0.8 \\
\hline 160 & 36.9 & 24.1 & 21.5 & 23.7 \\
\hline $16: 1(n-7)$ & 3.4 & 4.3 & 1.0 & 1.6 \\
\hline $16: 2$ & 0.2 & 0.8 & 0.3 & 0.5 \\
\hline $18: 0$ & 9.7 & 7.1 & 5.3 & 5.6 \\
\hline $18: 1(n-9)$ & 4.3 & 11.2 & 16.5 & 17.7 \\
\hline $18: 2(n-6)$ & 1.1 & 1.1 & 3.4 & 2.8 \\
\hline $18: 3(n-6)$ & 2.4 & 1.2 & 0.8 & 0.8 \\
\hline $18: 4(n-3)$ & 0.7 & 0.5 & 0.4 & 0.4 \\
\hline $20: 0$ & 0.8 & 0.9 & 0.4 & 0.4 \\
\hline $20: 1$ & 0.5 & 0.8 & 1.6 & 1.8 \\
\hline $20: 2(n-6)$ & 0.5 & 0.6 & 1.4 & 1.2 \\
\hline $20: 3(n-6)$ & 7.9 & 8.2 & 4.7 & 5.2 \\
\hline $20: 4(n-6)$ & 2.0 & 1.8 & 1.4 & 1.1 \\
\hline $20: 4(n-3)$ & 0.7 & 0.7 & 0.6 & 0.6 \\
\hline $20: 5(n-3)$ & 3.3 & 0.7 & 0.5 & 0.5 \\
\hline $22: 3(n-6)$ & 0.6 & 0.9 & 0.8 & 0.6 \\
\hline $22: 4(n-6)$ & 0.6 & 0.7 & 1.1 & 1.0 \\
\hline $22: 5(n-6)$ & - & - & - & - \\
\hline $22: 5(n-3)$ & 1.9 & 1.7 & 2.0 & 1.8 \\
\hline $22: 6(n-3)$ & 18.2 & 22.9 & 35.1 & 31.1 \\
\hline Saturated & 51.0 & 35.0 & 28.2 & 31.0 \\
\hline
\end{tabular}

Family Poritidae (Table 4). Most characteristic for these corals were high amounts of $\gamma$-linolenic acid [18:3(n-6)]. Two species of Goniopora had similar fatty acid compositions, but differed in $(n-3) /(n-6)$ ratio. Porites lutea had a low level of PUFA, and a high proportion $(49.1 \%)$ of $16: 0$ acid.
Family Dendrophyllidae (Table 4). This family has a special position among scleractinian corals, because of the absence of symbiotic zooxanthellae (Patton et al. 1983). In accordance with this, Dendrophyllidae essentially differed from other families in composition of fatty acids. Thus, in Tubastrea coccinea the content of monoenoic acids, where 18:1(n-9) acid prevails, was highest. The fatty acids of the $(n-6)$ series are represented mainly by arachidonic and docosatetraenoic $[22: 4(n-6)]$ acids. Dominating among the fatty acids of the $(n-3)$ series were $20: 5(n-3)$ and $22: 5(n-3)$, while the proportion of docosahexaenoic acid [22:6(n-3)], the main PUFA in hermatypic corals, did not exceed $1 \%$.

Class Hydrozoa; Family Milleporidae (Table 5). Two species from the Seychelles and one from the South China Sea were examined. Milleporidae from various habitats of the Seychelles had practically the same fatty acid composition of lipids. The total PUFA content, with docosahexaenoic acid as the main component, was $51 \%$, while in Milleporidae species from Vietnam docosahexaenoic acid dominated with $61.5 \%$. The second major PUFA for all Milleporidae was $22: 5(n-6)$, though scleractinian corals do not have it at all or only in traces.

\section{DISCUSSION}

Corals are rich in lipids, which are the main biochemical link of the coral-zooxanthellae symbiotic association (Kellogg \& Patton 1983, Patton \& Burris 1983). Lipid content of these symbionts may reach 30 to $40 \%$ by dry weight of soft tissues of the host/symbiont association (Patton et al. 1983, Stimson 1987).

Earlier assays of coral lipids showed that saturation of fatty acids is unusually high for marine organisms, which may be explained by the biosynthetic activity of zooxanthellae. However, later studies revealed that practically all examined representatives of the order Scleractinia and Milleporidae have relatively large PUFA contents (Meyers 1979, Patton et al. 1983). Similar results were obtained in this work. High levels of $18: 3(n-6)$ and $20: 3(n-6)$ acids were characteristic of all the examined Anthozoa (except the non-zooxanthellate Dendrophyllidae). Zooxanthellae are their probable source, as it was earlier shown that zooxanthellae glycolipids contained $18: 3(n-6)$ acid as the main component (Bishop \& Kenrick 1980). Corals without zooxanthellae have low contents of polyenoic C18 and $20: 3(n-6)$ acids, but high levels of $18: 1(n-9)$ and $22: 5(n-3)$ acids are characteristic for them.

PUFA of the $(n-3)$ and $(n-6)$ series are vital for normal activity of all animals, including marine invertebrates (Tinoco 1982). The general pathways of fatty acid biosynthesis are shown in Fig. 1 
Table 4. Fatty acid composition of total lipids of scleractinian corals: families Poritidae and Dendrophyllidae. (\% of total fatty acids; values more than $0.2 \%$ are given). PUFA: polyunsaturated fatty acids

\begin{tabular}{|c|c|c|c|c|c|}
\hline \multirow{2}{*}{$\begin{array}{l}\text { Fatty } \\
\text { acids }\end{array}$} & \multicolumn{3}{|c|}{ Anthozoa: Poritidae } & \multicolumn{2}{|c|}{ Anthozoa: Dendrophyllidae } \\
\hline & $\begin{array}{l}\text { Porites lutea } \\
\text { Vietnama }\end{array}$ & $\begin{array}{l}\text { Goniopora sp. } 1 \\
\text { Vietnam }^{\mathrm{b}}\end{array}$ & $\begin{array}{l}\text { Goniopora sp. II } \\
\text { Vietnam }^{\mathrm{b}}\end{array}$ & $\begin{array}{l}\text { Tubastrea coccinea } \\
\text { Seychelles }\end{array}$ & $\begin{array}{c}\text { Tubastrea micrantha } \\
\text { Seychelles }\end{array}$ \\
\hline $14: 0$ & 5.4 & 2.2 & 2.0 & 0.9 & 0.5 \\
\hline $16: 0$ & 49.1 & 17.2 & 15.0 & 7.2 & 6.4 \\
\hline $16: 1(n-7)$ & 1.9 & 3.5 & 2.3 & 5.9 & 3.7 \\
\hline $16: 2$ & 0.7 & 0.5 & 1.2 & 3.1 & 2.9 \\
\hline $18: 0$ & 7.2 & 5.7 & 6.8 & 4.2 & 6.7 \\
\hline $18: 1(n-9)$ & 3.8 & 11.7 & 6.6 & 23.3 & 26.4 \\
\hline $18: 2(n-6)$ & 1.0 & 2.2 & 1.6 & 2.0 & 1.8 \\
\hline $18: 3(n-6)$ & 9.7 & 4.5 & 6.2 & 0.4 & 0.3 \\
\hline $18: 4(n-3)$ & 2.9 & 2.3 & 4.3 & 0.7 & 0.8 \\
\hline $20: 0$ & 1.0 & - & - & 0.4 & 1.0 \\
\hline $20: 1$ & 0.9 & 5.9 & 2.9 & 3.0 & 3.2 \\
\hline $20: 2(n-6)$ & - & 1.7 & 1.4 & 0.9 & 1.6 \\
\hline $20: 3(n-6)$ & 1.6 & 3.6 & 2.9 & 0.8 & 0.5 \\
\hline $20: 4(n-6)$ & 2.3 & 13.3 & 21.9 & 7.8 & 6.6 \\
\hline $20: 4(n-3)$ & 0.3 & 0.7 & 1.1 & 0.9 & 1.0 \\
\hline $20: 5(n-3)$ & 3.3 & 4.1 & 4.6 & 14.9 & 10.9 \\
\hline $22: 3(n-6)$ & - & 0.4 & 0.3 & 0.5 & 0.3 \\
\hline $22: 4(n-6)$ & 1.4 & 3.3 & 6.0 & 4.7 & 5.5 \\
\hline $22: 5(n-6)$ & - & - & - & - & - \\
\hline $22: 5(n-3)$ & 0.8 & 1.0 & 0.8 & 16.4 & 17.3 \\
\hline $22: 6(n-3)$ & 5.3 & 15.7 & 11.5 & 1.4 & 1.3 \\
\hline Saturated & 62.8 & 25.1 & 23.1 & 12.7 & 14.6 \\
\hline PUFA & 29.3 & 53.8 & 68.9 & 52.0 & 49.5 \\
\hline$(n-3) /(n-6)$ & 0.8 & 0.8 & 0.5 & 2.1 & 1.9 \\
\hline \multicolumn{6}{|c|}{ a Thotyu Island } \\
\hline \multicolumn{6}{|c|}{ ' Tyam Island } \\
\hline${ }^{c}$ Aldabra Isla & & & & & \\
\hline
\end{tabular}

Corals exhibit polytrophic feeding with 3 main pathways of various intensity depending on the degree of specialization of species or on their ecological situation (Schlichter et al. 1984). Earlier, it was shown by Meyers (1979) that the degree of unsaturation of coral fatty acids may be an indicator of food source.

The productivity of the coral-zooxanthellae association depends on the efficiency of photosynthesis in zooxanthellae. However, photosynthesis depends in turn on light intensity and on the spectral characteristics of the sunlight. These parameters change considerably with depth (Leletkin \& Zvalinsky 1981). Meyers et al. (1978) attempted to establish a relationship between fatty acid composition and habitat depth. However, they did not find any such dependence in total lipids of the corals Montastrea annularis and Stephanocoenia michelinii. In our study morphological forms of Stylophora pistillata living in the depth range from 3 to $35 \mathrm{~m}$ had different fatty acid compositions of polar and neutral lipids (Table 3). Based on these results, it is difficult to draw unambiguous conclusions. High levels of 18:3(n-6) and 18:4(n-3) acids at depths 25 and $35 \mathrm{~m}$ may be connected with an increasing amount of zooxanthellae with depth. Inhibition of photosynthesis in some unicellular algae is associated with decreased biosynthesis of 20:5(n-3) acid and simultaneous increased biosynthesis of arachidonic acid (Radwan et al. 1988).

There are definite differences in biosynthesis pathways and in fatty acid composition in corals and zooxanthellae. These differences may help us to determine contributions of the symbiotic alga and host animal to the total 'pool' of fatty acids. We believe that further research should investigate relationship of fatty acids biosynthesis by zooxanthellae and the 'host' coral.

The low level of PUFA in corals may indicate that saturated fatty acids are synthesized and then transmitted to the 'host' coral by symbiotic zooxanthellae (Patton et al. 1977). These data were confirmed in studies on biosynthesis of fatty acids from ${ }^{14} \mathrm{C}$-acetate by zooxanthellae (Blanquet et al. 1979, Patton et al. 1983). However it seems that significant differences in fatty acid composition of corals cannot be explained only by utilization of external food sources and by zooxanthellae function, but most involve biosynthesis of fatty acids by the 'host'.

The prevalence of $(n-3)$ acids is typical of marine organisms. However, some Acroporidae and all 
Poritidae had higher contents of $(n-6)$ acids (Tables 1 \& $4)$. In the corals of class Anthozoa, the main ( $n-3)$ acids are $20: 5(n-3)$ and $22: 6(n-3)$, except for the family Dendrophyllidae, where 22:5(n-3) prevails. An analysis of fatty acids of total lipids of 2 Tubastrea species

Table 5. Fatty acid composition of total lipids of Hydrozoa corals: family Milleporidae (\% of total fatty acids; values more than $0.2 \%$ are given). PUFA: polyunsaturated fatty acids

\begin{tabular}{|c|c|c|c|}
\hline \multirow{2}{*}{$\begin{array}{l}\text { Fatty } \\
\text { acids }\end{array}$} & \multicolumn{3}{|c|}{ Hydrozoa: Milleporidae } \\
\hline & $\begin{array}{l}\text { Millepora sp. } \\
\text { Vietnam }\end{array}$ & $\begin{array}{l}\text { Millepora } \\
\text { platyphylla } \\
\text { Seychelles }^{b}\end{array}$ & $\begin{array}{l}\text { Millepora } \\
\text { dichotoma } \\
\text { Seychelles }^{\mathrm{b}}\end{array}$ \\
\hline $14: 0$ & 0.6 & 0.8 & 1.4 \\
\hline $16: 0$ & 6.3 & 17.6 & 18.9 \\
\hline $16: 1(n-7)$ & - & 0.2 & - \\
\hline $16: 2$ & 0.2 & 0.8 & 0.4 \\
\hline 18:0 & 7.1 & 21.3 & 19.4 \\
\hline $18: 1(n-9)$ & 1.4 & 2.4 & 3.2 \\
\hline $18: 2(n-6)$ & 0.6 & 0.4 & 0.7 \\
\hline $18: 3(n-6)$ & - & 0.2 & 0.4 \\
\hline $18: 4(n-3)$ & 6.9 & 5.2 & 4.8 \\
\hline $20: 0$ & - & - & - \\
\hline $20: 1$ & 0.3 & 6.3 & 6.1 \\
\hline $20: 2(n-6)$ & - & 0.5 & 0.4 \\
\hline $20: 3(n-6)$ & 0.4 & - & - \\
\hline $20: 4(n-6)$ & 0.4 & 0.3 & 1.0 \\
\hline $20: 4(n-3)$ & 0.4 & 0.2 & - \\
\hline $20: 5(n-3)$ & 1.1 & 0.4 & 0.6 \\
\hline $22: 3(n-6)$ & - & - & - \\
\hline $22: 4(n-6)$ & 3.8 & 4.6 & 3.7 \\
\hline $22: 5(n-6)$ & 8.3 & 10.0 & 8.5 \\
\hline $22: 5(n-3)$ & - & 0.7 & 0.9 \\
\hline $22: 6(n-3)$ & 61.5 & 27.5 & 28.0 \\
\hline Saturated & 14.0 & 39.0 & 40.0 \\
\hline PUFA & 83.9 & 51.0 & 49.6 \\
\hline$(n-3) /(n-6)$ & 5.1 & 2.0 & 2.3 \\
\hline $\begin{array}{l}\text { Thotyu Islar } \\
\text { Aldabra Isl }\end{array}$ & & & \\
\hline
\end{tabular}

showed peculiarities caused mainly by external food source. Nevertheless, in contrast to $22: 6(n-3), 22: 5(n-3)$ is found in plankton only in traces (Tinoco 1982). Joseph (1979), working with the medusa Maeotias inexpecta, presumed that $22: 5(n-3)$ [also 22:4(n-6)] can be accumulated in the organism due to the low activity of $\Delta 4$-desaturase (Fig. 1).

This assumption has not been checked out experimentally, but a similar redistribution of $(n-3)$ acids was noted also for the marine anemone Phymactis clematis (Pollero 1983). The presence of considerable amounts of oleic acid in both Tubastrea species indicates that phytoplankton is the most probable source of fatty acids in these organism (Fig. 1). The $\Delta 5$-desaturase acts on $20: 3(n-6)$ and $20: 4(n-3)$ acids to form key icosapolyenoic acids of the $(n-3)$ and $(n-6)$ series. Thus, deficit of $\Delta 5$-desaturase activity must cause an increase of the pool of $20: 3(n-6)$ and $20: 4(n-3)$ acids, with a simultaneous decrease of the pool of 20:4(n-6) and 20:5(n-3). Probably, a similar mechanism forms the basis of redistribution of these acids in Pocilloporidae (Table 2). The abundance of Milleporidae may reach from 25 to $100 \%$ of reef coverage. Although these corals, analogous to Scleractinia, possess zooxanthellae, the choice of habitat is not limited by light. Three morphologically different forms have been described in Millepora dichotoma with 3 types of feeding (Moishcenko 1989). Previously, Meyers et al. (1974) noted an unusual composition of fatty acids in 2 Milleporidae species from the Caribbean Sea and Eniwetok Atoll (Pacific Ocean). PUFA were not found in lipids of these animals, while saturated acids accounted for more than $95 \%$ of total acid content. High levels of PUFA, mostly $22: 5(n-6)$ and $22: 6(n-3)$, were most noticeable in the species examined in the present study. These acids are obtained by the action of $\triangle 4$-desaturase on $22: 4(n-6)$ and 22:5(n-3) (Fig. 1). However, 22:5(n-6) and

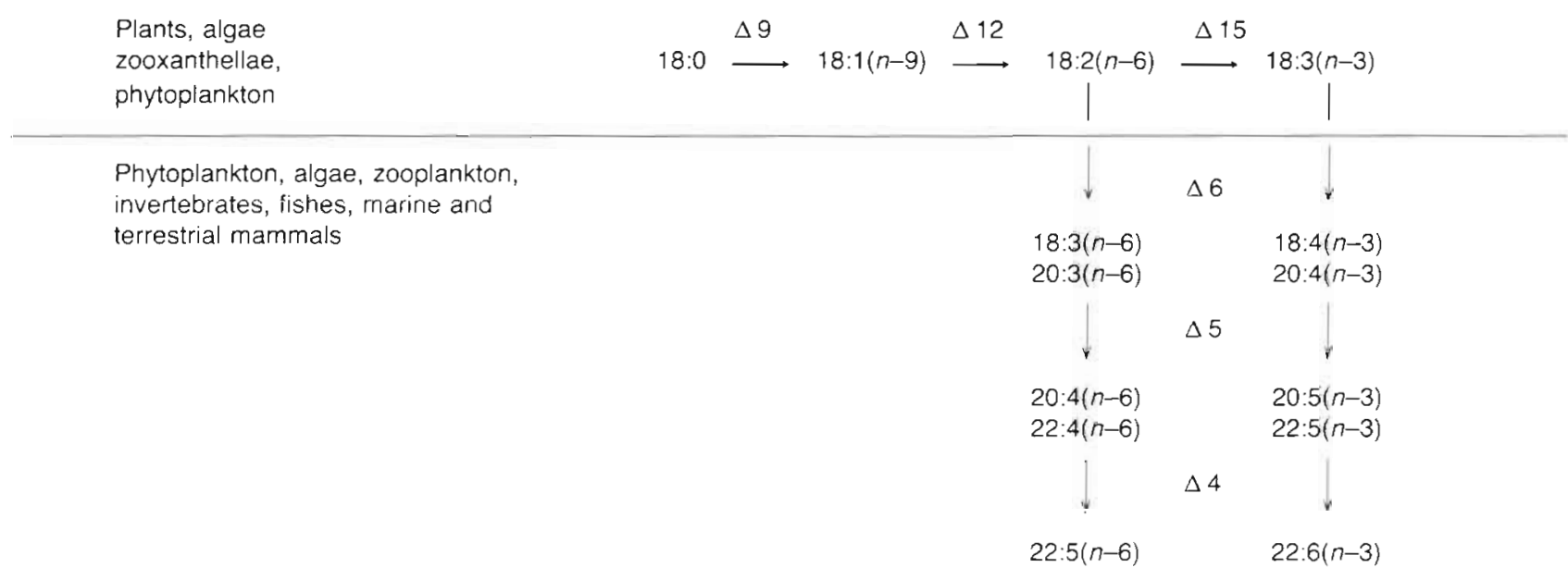

Fig. 1. Major pathways for synthesis of PUFA $(n-3)$ and $(n-6)$ series from linolenic $18: 3(n-3)$ and linoleic $18: 2(n-6)$ acids $($ Connor \& Neuringer 1988). $\Delta 4, \Delta 5, \Delta 6, \Delta 12$ and $\Delta 15$ denote corresponding desaturases 
22:6(n-3) acids in Milleporidae seem to have different origins (Table 5). A major portion of docosahexaenoic acid can be supplied from external food sources, while $22: 5(n-6)$ is a metabolite of coral $\Delta 4$-desaturase.

Many authors have shown that biosynthesis of PUFA in marine invertebrates is a complicated and interspecifically variable process. We have made an attempt to explain fatty acid composition of reef-building corals with reference to the ecological situation, the ways of feeding, the presence of symbionts and also the specific ways of PUFA biosynthesis.

Further research is needed to study interactions between the systems of biosynthesis of fatty acids in zooxanthellae and 'host' coral.

Acknowledgements. The authors extend great appreciation to Prof. Andrew A. Benson of the Scripps Institution of Oceanography (La Jolla, California, USA) for valuable discussion. We are most grateful to Prof. Leonard Muscatine of the University of California (Los Angeles) for careful reading of the finished copy. We thank Sergey Kasyanov of the Institute of Marine Biology for skillful help in this research. Thanks are also due to V M. Savruev and Irina A. Barsegova for preparation of the English text of the paper.

\section{LITERATURE CITED}

Benson, A. A., Muscatine, L. (1974). Wax in coral mucus: energy transfer from corals to reef fishes. Limnol. Oceanogr. 19: 810-814

Bishop, D. C., Kenrick, J. R. (1980). Fatty acid composition of symbiotic zooxanthellae in relation to their hosts. Lipids 15: 799-804

Blanquet, R. S., Nevenzel, J. C., Benson, A. A. (1979). Acetate incorporation into the lipids of the anemone Anthopleura elegantissima and its associated zooxanthellae. Mar. Biol. 54: $185-194$

Carreau, J. P., Dubacq, J. P. (1978). Adaptation of a macroscale method to the micro-scale for fatty acid methyl transesterification of biological lipid extracts. J. Chromatogr. 151: 384-390

Connor, W. E., Neuringer, M. (1988). The effects of $n-3$ fatty acid deficiency and repletion upon the fatty acid composition and function of the brain and retina. Prog. clin. biol. Res. 282: 275-294

Flanzy, J., Bondon, M., Leger, C., Pihet, J. (1976). Application of Carbowax 20M as an open-tubular liquid phase in analysis of nutritionally important fats and oils. J. Chromatogr. Sci. 14: 17-24

Joseph, J. D. (1979). Lipid composition of marine and estuarine invertebrates: Porifera and Cnidaria. Prog. Lipid Res. 18: 1-30

Kellogg, R. B., Patton, J. S. (1983). Lipid droplets, medium of energy exchange in the symbiotic anemone Condylactis gigantea: a model coral polyp. Mar. Biol. 75: 137-149

Latypov, Y. Ya., Latyshev, N. A., Khotimchenko, S. V. (1988). The fatty acid composition and the systematic position of

This article was submitted to the editor reef-building corals. Proc. VI Int. Coral Reef Symp. Townsville, p. 235

Leletkin, V A., Zvalinsky, V I. (1981). Photosynthesis of coral zooxanthellae from different depths. Proc. IV Int Coral Reef Symp., Manila, p. 33-37

Meyers, P. A. (1977). Fatty acids and hydrocarbons of Caribbean corals. In: Proc. III Int. Coral Reef Symp., Miami, p. 529-536

Meyers, P. A. (1979). Polyunsaturated fatty acids in coral: indicators of nutritional sources. Mar Biol. Lett. 1: 69-75

Meyers, P. A., Porter, J. W., Chad, R. L. (1978). Depth analysis of fatty acids in two Caribbean reef corals. Mar Biol. 49: 192-202

Meyers, P. A., Quinn, J. G., Marshall, N. (1974). A method for analysis of fatty acids in coral. Limnol. Oceanogr. 19: 846-848

Moishcenko, A. V. (1989). The problem of a species criterion of the genus Millepora (Cnidaria, Hydrozoa) from South Vietnam. In: Koltun, V M., Marfenin, N. N., Stepanyants, S. D. (eds.) The fundamental investigation of the Recent Porifera and Coelenterata. Zoological Institute of the Soviet Academy of Sciences, Leningrad, p. 84-86 (in Russian)

Muscatine, L. (1980). Productivity of zooxanthellae. In: Falkowski, P. G. (ed.) Primary productivity in the sea. Plenum Press, New York, p. 381-402

Patton, J. S., Abraham, S., Benson, A. A. (1977). Lipogenesis in the coral Pocillopora capitata and its isolated zooxanthellae: evidence for a light-driven carbon cycle between symbiont and host. Mar. Biol. 44: 235-247

Patton, J. S., Battey, J. F., Rigler, M. W., Porter, J. W., Black, C. C., Burris, J. E. (1983). A comparison of the metabolism of bicarbonate ${ }^{14} \mathrm{C}$ and acetate $1-{ }^{14} \mathrm{C}$ and the variability of species lipid composition in reef corals. Mar Biol. 75 : $121-130$

Patton, J. S., Burris, J. E. (1983). Lipid synthesis and extrusion by freshly isolated zooxanthellae (symbiotic algae). Mar. Biol. 75: 131-136

Pollero, R. J. (1983). Lipid and fatty acid characterization and metabolism in the sea anemone Phymactis clematis (Dana). Lipids 18: 12-17

Radwan, S. S., Shaaban, A. S., Gebreel, H. M. (1988). Arachidonic acid in the lipids of marine algae maintained under blue, white and red light. Z. Naturforsch. $43 \mathrm{C}$ : $15-18$

Schlichter, D. (1982). Nutritional strategies of cnidarians: the absorption, translocation and utilization of dissolved nutrients by Heteroxenia fuscescens. Am. Zool. 22: 659-669

Schlichter, D., Kremer, B. P., Svoboda, A. (1984). Zooxanthellae providing assimilator power for the incorporation of exogenous acetate in Heteroxenia fuscescens (Cnidaria: Alcyonaria). Mar. Biol. 83: 277-286

Stimson, J. S. (1987). Location, quantity and rate of change in quantity of lipids in tissue of Hawaiian hermatypic corals. Bull. mar. Sci. 41: 889-904

Tinoco, J. (1982). Dietary requirements and function of alphalinolenic acid in animals. Prog. Lipid Res. 21: 1-45

Wells, J. W. (1956). Scleractinia. In: Moore, R. C. (ed.) Treatise on invertebrates. Paleontology Coelenterata. Geol. Soc. Am., Univ. Kansas Press, p. 328-440

Manuscript first received: September 19, 1990

Revised version accepted: April 4, 1991 